\title{
A Curious Case of Breast Tissue Expander
}

\author{
Subhashish Agarwal, MD, MS ${ }^{1 *}$, Nishant Verma, MD, MPH${ }^{1}$, John Y.S. Kim, MD², Bradley P. Knight, \\ $M D^{1}$, Alexandru Chicos, MD' \\ ${ }^{1}$ Division of Cardiology, Electrophysiology Section, Northwestern University, Chicago, Illinois, USA \\ ${ }^{2}$ Division of Plastic Surgery, Department of Surgery, Northwestern University, Chicago, Illinois, USA
}

\begin{abstract}
We present a case of an individual who was found to be emanating a sound from her implantable cardioverter defibrillator (ICD). She had developed breast carcinoma requiring mastectomy and breast tissue expander implantation. The magnetic port on the breast tissue expander led to electromagnetic interference and magnet mode conversion. The ICD's conversion to magnet mode can be dangerous, because it blocks tachyarrhythmia detection and therapy.

Copyright (c) 2015 Science International Corp.
\end{abstract}

\section{Key Words}

Implantable Cardiac Defibrillator - Breast Tissue Expander • Magnet Mode Reversion • Interference • Implantable cardiac defibrillator

\section{Case}

A 57-year-old female presented to our facility with emission of a low-frequency hum emanating from her implantable cardioverter defibrillator (ICD). The tone increased in frequency and duration over the previous 5 days. She was diagnosed with hypertrophic cardiomyopathy in 2004 with high-risk features, a history of nonsustained ventricular tachycardia, septal thickness of $29 \mathrm{~mm}$, and a family history of unexplained death in two maternal uncles. The patient underwent implantation of a single-chamber, dual coil Medtronic Protecta XT ICD for primary prevention in 2004 and a generator change in 2012. She subsequently developed ductal carcinoma in situ of the left breast in October 2013,

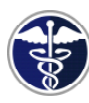

Fax +1 2037853346

E-Mail: agr@scienceinternational.org

http://arrhythmiagr.com/ (c) 2015 Arrhythmia Grand Rounds

Published by Science International Corp. ISSN 2326-4012

Accessible online at: http://arrhythmiagr.com/ leading to a bilateral mastectomy, breast tissue expander implantation, and repositioning of her ICD generator superior to her previous pocket in November 2013.

She reported no chest pain, trauma, shortness of breath, syncope, lightheadedness, palpitations, any pain to extremities, or any systemic complaint. She reported no history of defibrillator shocks in the past 12 years.

Her device interrogation revealed appropriate device function, with adequate sensing, impedance, and capture thresholds with intact lead integrity. A chest roentgenogram is shown in Figure 1. Further review of the patient's history revealed that in January 2014, she began receiving gradual filling of her tissue expanders with saline by plastic surgery. The device tone began after the third saline infusion. Therefore, it was suspected that the gradual filling of the tissue expanders was somehow related to her device malfunction.

A review of the literature indicated that some breast tissue expanders have magnetic ports to allow for a more accurate detection of the injection site. ICD tachytherapy is routinely deactivated by magnet application. Tikkaja et al. [1] reported a case of ICD tachytherapy deactivation by a laptop computer. There has been an isolated report of breast tissue expander magnet dislodgement with magnetic resonance imaging [2].

Plastic surgery was consulted and tissue expander decompression resulted in the resolution of the alert tone. In an ex vivo environment, the Medtronic ICD and the breast tissue expander

*Corresponding Author:

Subhashish Agarwal, MD, MS

Northwestern University School of Medicine

Chicago, Illinois 60611, USA

Tel.: +1 773865 9426, E-Mail: sa1972@gmail.com 


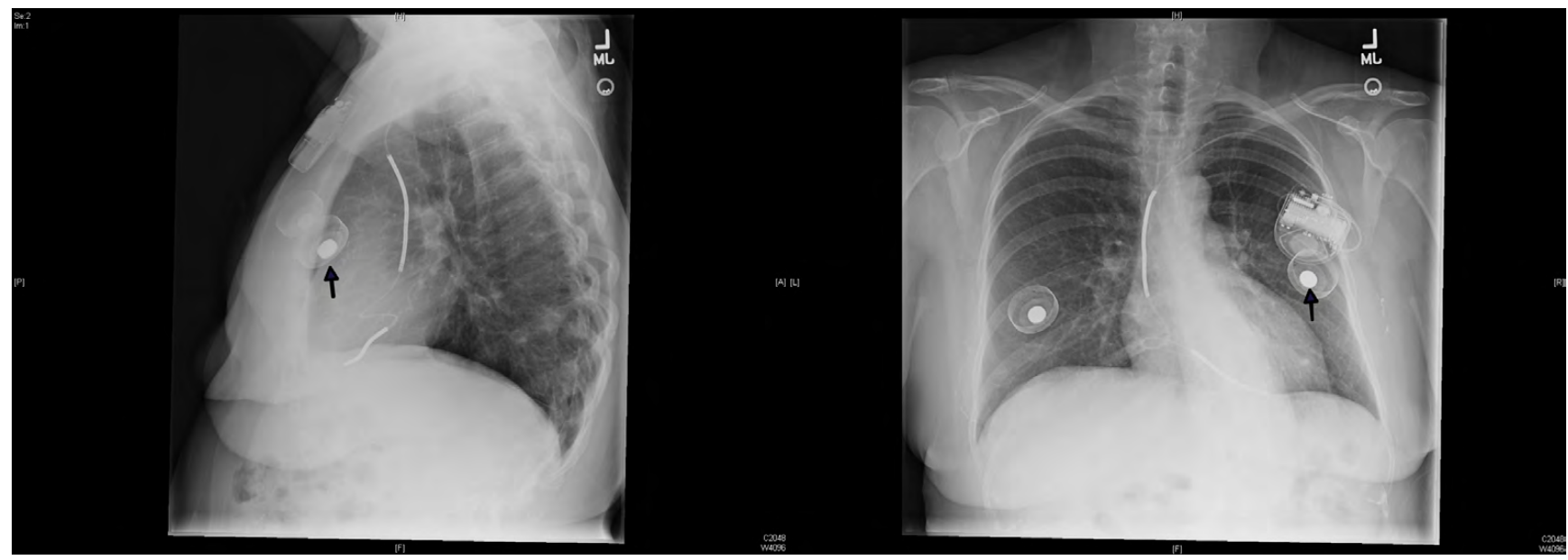

Figure 1. PA and lateral chest roentgenograms depicting proximity of the intracardiac defibrillator and the breast tissue expander and magnet (black arrows).

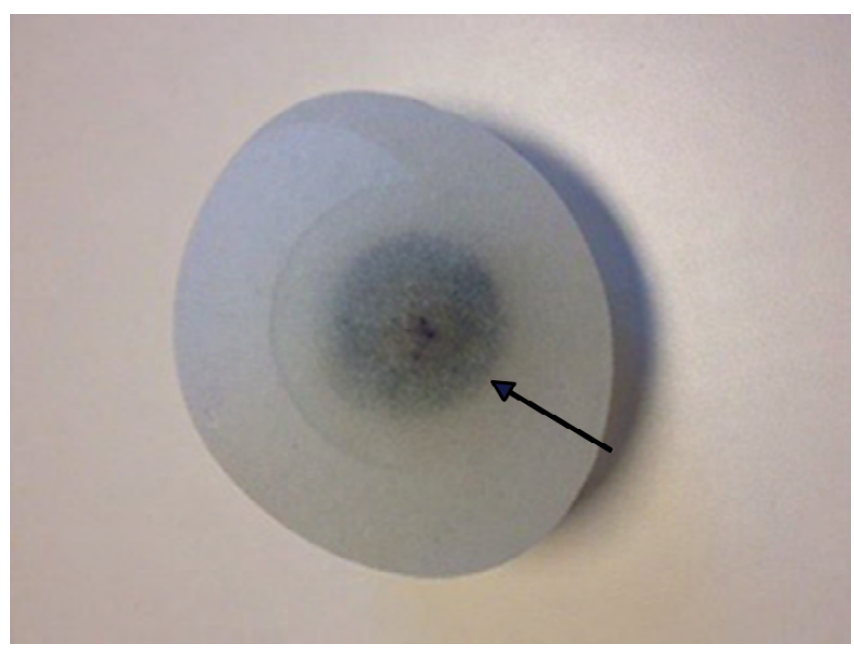

Figure 2. Ex vivo breast tissue expander with magnet (black arrow).

(Figure 2) were brought into close proximity. At a distance of approximately $1 \mathrm{~cm}$, a similar magnetic interaction hum was generated from the ICD with suspension of tachycardia therapy on the monitor. Subsequently, it was deduced that the
ICD was deactivated by the magnet in the tissue expander port. In the interim, the breast tissue expanders were removed with resolution of patient's symptoms.

This is a novel case that illustrates the interplay between magnetic tissue expander location and defibrillator function. It serves as a reminder that breast tissue expanders or prosthetic devices with a magnet can result in failures to sense tachyarrhythmias and deliver appropriate therapy. It also highlights the need for added vigilance and electrophysiology collaboration for patients requiring magnetic prosthetic devices and an implantable defibrillator.

\section{Conflict of Interest}

The authors have no conflicts of interest relevant to this publication.

\section{Comment on this Article or Ask a Question}

\section{References}

1. Tikkaja M, Aro A, Alanko T, Lindholm $\mathrm{H}$, Hietanen $M$. Inappropriate implantable cardioverter-defibrillator magnet-mode switch induced by a laptop computer. Pacing Clin Electrophysiol. 2012;35(6):e177-178. DOI: 10.1111/j.1540-8159.2012.03330.x
2. Zegzula HD, Lee WP. Infusion port dislodgement of bilateral breast tissue expanders after MRI. Ann Plast Surg. 2001;46:46-48. PMID: 11192033
Cite this article as: Agarwal $\mathrm{S}$, Verma N, Kim JYS, Knight BP, Chicos A. A Curious Case of Breast Tissue Expander. Arrhythmia Grand Rounds 2015;1(2):56-57. DOI: http://dx.doi. org/10.12945/j.agr.2015.019-14 